\title{
Insulin Resistance as a Predictor of the Late Catch-up Phenomenon After Drug-Eluting Stent Implantation
}

\author{
Takaaki Komatsu, MD, PhD; Sachiko Komatsu, MD, PhD; Hidehiko Nakamura, MD; \\ Takanori Kuroyanagi, MD, PhD; Akinori Fujikake, MD, PhD; Itaru Hisauchi, MD; \\ Masashi Sakuma, MD, PhD; Shiro Nakahara, MD, PhD; \\ Yoshihiko Sakai, MD, PhD; Isao Taguchi, MD, PhD
}

\begin{abstract}
Background: Percutaneous coronary intervention $(\mathrm{PCl})$ is an effective treatment for patients with ischemic heart disease. In particular, restenosis is suppressed after drug-eluting stent (DES) implantation. However, several problems remain. Previously, we reported neointimal proliferation after DES implantation, which was associated with insulin resistance (IR). The aim of the present study was to clarify whether IR is associated with mortality and major adverse cardiac and cerebrovascular events (MACCE) after 1st-generation DES implantation.
\end{abstract}

Methods and Results: We researched the clinical records of 109 patients who had undergone elective $\mathrm{PCl}$ and DES implantation between May 2007 and December 2010. We segregated these patients according to the value of the homeostasis model assessment of IR (HOMA-IR) into Group P ( $n=63$; HOMA-IR $\geq 2.5$, positive) and Group N ( $n=46$; HOMA-IR <2.5, negative), and examined the relationship between HOMA-IR and MACCE. The observation period was 7.4 \pm 1.6 years. There were no differences between the 2 groups in the occurrence of all-cause death, cardiac death, restenosis, myocardial infarction, stroke, heart failure, or stent thrombosis. However, the late catch-up phenomenon was significantly more common in Group P than in Group N (12.7\% vs. 2.2\% P=0.048).

Conclusions: IR is a useful predictor of the late catch-up phenomenon after DES implantation, and improvement of IR may help to prevent the phenomenon. (Circ $J$ 2016; 80: 657-662)

Key Words: Drug-eluting stents; Insulin resistance; Late catch-up phenomenon

$\mathbf{P}$ ercutaneous coronary intervention (PCI) has been widely confirmed as an effective treatment strategy for patients with ischemic heart disease. However, despite the development of new drug-eluting stents (DES) that may decrease the rate of restenosis, several problems remain, such as stent thrombosis and the late catch-up phenomenon. Insulin resistance (IR) is associated with hypertension, glucose intolerance, obesity, and dyslipidemia, all of which are established risk factors for coronary artery disease (CAD) ${ }^{1-3}$ IR is associated with an increased incidence of cardiovascular disease, even before the onset of diabetes mellitus (DM). ${ }^{4,5}$ Previously, we reported neointimal proliferation after DES implantation that was associated with IR. ${ }^{6}$ In addition, even in patients undergoing hemodialysis, which is one of the strongest predictors for cardiovascular events, DM is an independent predictor of long-term adverse events after DES implantation. ${ }^{7}$ Therefore, there seems to be much room for improvement of dia- betic treatment. The aim of the present study was to clarify whether IR is associated with mortality and major adverse cardiac and cerebrovascular events (MACCE) after DES implantation.

\section{Editorial p592}

Methods
Study Design
We studied 109 patients who had undergone elective PCI and
DES implantation between May 2007 and December 2010.
All patients in whom stenting was successful gave informed
consent to participate in the study. Coronary angiography
(CAG) was carried out in all patients using AXIOM Artis dBC
(SIEMENS Company Inc, Erlangen, Germany), and PCI was
performed for lesions with significant stenosis. Lesions were

Received September 24, 2015; revised manuscript received December 24, 2015; accepted December 27, 2015; released online January 27 , 2016 Time for primary review: 19 days

Department of Cardiology, Dokkyo Medical University Koshigaya Hospital, Saitama (T. Komatsu, S.K., H.N., T. Kuroyanagi, A.F., I.H., S.N., Y.S., I.T.); Department of Cardiology Cardiovascular Medicine, Dokkyo Medical University School of Medicine, Tochigi (M.S.), Japan

Mailing address: Takaaki Komatsu, MD, PhD, Department of Cardiology, Dokkyo Medical University Koshigaya Hospital, 2-1-50 Minamikoshigaya, Koshigaya, Saitama 343-8555, Japan. E-mail: takaaki_km2@yahoo.co.jp

ISSN-1346-9843 doi:10.1253/circj.CJ-15-1012

All rights are reserved to the Japanese Circulation Society. For permissions, please e-mail: cj@j-circ.or.jp 


\begin{tabular}{|lccc|}
\hline Table 1. Baseline Characteristics of Study Patients Undergoing Elective PCI and DES Implantation \\
& $\begin{array}{c}\text { Group P } \\
(\mathbf{n}=63)\end{array}$ & $\begin{array}{c}\text { Group N } \\
(\mathbf{n}=46)\end{array}$ & P value \\
Age (years) & $64.8 \pm 8.1$ & $69.4 \pm 9.1$ & 0.407 \\
Sex (M/F) & $47 / 16$ & $37 / 9$ & 0.475 \\
Risk factors & & & \\
Hypertension (n, \%) & $42(66.7)$ & $31(67.4)$ & 0.937 \\
$\quad$ Systolic blood pressure (mmHg) & $138.4 \pm 25.5$ & $134.7 \pm 23.5$ & 0.445 \\
$\quad$ Diastolic blood pressure (mmHg) & $68.6 \pm 11.4$ & $69.2 \pm 12.8$ & 0.799 \\
Diabetes mellitus (n, \%) & $15(23.8)$ & $7(15.2)$ & 0.270 \\
Fasting glucose (mg/dl) & $121.3 \pm 22.3$ & $106.2 \pm 18.0$ & $<0.001$ \\
HbA1c (\%) & $5.8 \pm 0.8$ & $5.7 \pm 1.0$ & 0.784 \\
HOMA-IR & $7.1 \pm 4.8$ & $1.7 \pm 0.5$ & $<0.001$ \\
Dyslipidemia (n, \%) & $39(61.9)$ & $26(56.5)$ & 0.572 \\
LDL-cholesterol (mg/dl) & $112.7 \pm 34.9$ & $113.9 \pm 32.9$ & 0.854 \\
HDL-cholesterol (mg/dl) & $49.4 \pm 11.4$ & $52.0 \pm 14.8$ & 0.310 \\
Triglyceride (mg/dl) & $144.5 \pm 60.0$ & $135.1 \pm 47.5$ & 0.372 \\
Smoking (n, \%) & $31(49.2)$ & $20(43.5)$ & 0.554 \\
Family history (n, \%) & $11(17.5)$ & $5(10.9)$ & 0.337 \\
Drug treatment & & & 0.673 \\
ACEl or ARB & $40(63.5)$ & $31(67.4)$ & 0.937 \\
Statin & $42(66.7)$ & $31(67.4)$ & 0.975 \\
$\beta$-blocker & $19(30.2)$ & $14(30.4)$ & 0.472 \\
Ca-channel blocker & $29(46.0)$ & $18(39.1)$ & 0.691 \\
Sulfonylurea & $3(4.8)$ & $3(6.5)$ & 0.205 \\
a-glucosidase & $6(9.5)$ & $2(4.3)$ & 0.919 \\
Biganide & $3(4.8)$ & $2(4.3)$ & \\
\hline
\end{tabular}

$\mathrm{ACEI}$, angiotensin-converting enzyme inhibitor; ARB, angiotensin II receptor blocker; DES, drug-eluting stent; $\mathrm{PCI}$, percutaneous coronary intervention.

classified according to the modified American College of Cardiology (ACC)/American Heart Association (AHA) grading system (types A, B1, B2, and C).

All patients were taking aspirin $(100 \mathrm{mg} /$ day $)$, ticlopidine hydrochloride $(200 \mathrm{mg}$ /day) or clopidogrel sulfate $(75 \mathrm{mg} /$ day $)$. They received a heparin $(5,000 \mathrm{IU})$ bolus intravenously before the PCI in the absence of contraindications. Drug treatment of risk factors (eg, hypertension, dyslipidemia, DM) was provided as appropriate, but we excluded patients who were using pioglitazone hydrochloride or insulin, and/or who had a fasting glucose $>200 \mathrm{mg} / \mathrm{dl}$.

The HOMA-IR index is based on the levels of fasting glucose and plasma insulin. We used it as an index of IR, ${ }^{8,9}$ as calculated:

\section{[HOMA-IR=fasting glucose $(\mathrm{mg} / \mathrm{dl}) \times$ plasma insulin $(\mu \mathrm{U} / \mathrm{ml}) / 405]$}

In Japanese subjects, IR is considered to be present when the HOMA-IR index is $>2.5 .{ }^{10}$ Therefore, we divided the patients according to the value of the index into a Group $\mathrm{P}$ (HOMA-IR $\geq 2.5$, positive) and a Group N (HOMA-IR $<2.5$, negative). All patients were implanted with a 1st-generation DES (sirolimus-eluting stent or paclitaxel-eluting stent). The luminal diameter of the coronary artery and the degree of stenosis were measured before dilatation and after intervention, and again after 8 months of follow-up. Restenosis was defined as a stenosis of $\geq 50 \%$ of the luminal diameter. After enrollment, all patients had individualized, optimized therapies, including medication and lifestyle changes to reduce risk factors for $\mathrm{CAD}$ according to the AHA/ACC guidelines. ${ }^{11,12}$
All patients were followed up in the hospital or by visiting a physician's office every month, and were encouraged to adhere to the lifestyle changes and diet recommendations. After follow-up CAG, all patients were seen monthly in the hospital or until one of the following events occurred: death, cardiac death, myocardial infarction, stroke, heart failure, stent thrombosis, late catch-up phenomenon. Late catch-up phenomenon was defined as ischemia-driven target lesion revascularization (TLR), except for stent thrombosis after the 8-month follow-up CAG. Patients underwent CAG after the 8-month follow-up CAG whenever their periodic exercise test was interpreted as positive, or if they developed new-onset chest pain. The time to the first event was evaluated prospectively. The cause of death was determined from hospital records. All endpoint data were checked for accuracy, consistency, and completeness of follow-up by several investigators without knowledge of the patients' baseline characteristics. Additional information was obtained from the physicians as needed. Several other investigators were responsible for checking all data, for running the analysis, and for the security of the data files. The study was approved by the institutional review boards.

\section{Statistical Analysis}

Data are expressed as mean \pm SD. Comparisons between groups were performed by the Mann-Whitney $U$ test for continuous variables and by the Chi-square test for categorical variables. Kaplan-Meier analysis of event-free survival during follow-up was performed with stratification of patients based on the change in IR. All analyses were performed using the StatView 


\begin{tabular}{|c|c|c|c|}
\hline & $\begin{array}{c}\text { Group P } \\
(n=63)\end{array}$ & $\begin{array}{c}\text { Group N } \\
(n=46)\end{array}$ & $P$ value \\
\hline Stented coronary vessel & & & 0.891 \\
\hline LAD & 37 & 25 & \\
\hline LCX & 7 & 4 & \\
\hline $\mathrm{RCA}$ & 18 & 16 & \\
\hline LMT & 1 & 1 & \\
\hline No. of diseased vessels & & & 0.651 \\
\hline 1 & 18 & 17 & \\
\hline 2 & 23 & 15 & \\
\hline 3 & 22 & 14 & \\
\hline \multicolumn{4}{|l|}{ AHA type } \\
\hline $\mathrm{B} 2 \cdot \mathrm{C}(\mathrm{n}, \%)$ & $42(66.7)$ & $30(65.2)$ & 0.875 \\
\hline \multicolumn{4}{|l|}{ Stent } \\
\hline SES/PES & $52 / 11$ & $39 / 7$ & 0.755 \\
\hline Stent diameter (mm) & $3.04 \pm 0.32$ & $3.11 \pm 0.31$ & 0.379 \\
\hline Total stent length (mm) & $31.2 \pm 18.0$ & $31.7 \pm 22.0$ & 0.931 \\
\hline
\end{tabular}

LAD, left anterior descending; LCX, left circumflex; LMT, left main trunk; PES, paclitaxel-eluting stent; RCA, right coronary artery; SES, sirolimus-eluting stent. Other abbreviations as in Table 1.

\begin{tabular}{llcc|}
\hline \multicolumn{2}{l}{ Table 3. Rates of Restenosis and MACCE in Study Patients } & Undergoing Elective PCI and DES Implantation \\
& $\begin{array}{c}\text { Group } \mathbf{P} \\
(\mathbf{n}=63)\end{array}$ & $\begin{array}{c}\text { Group N } \\
(\mathbf{n}=\mathbf{4 6})\end{array}$ & P value \\
Restenosis (n, \%) & $8(12.7)$ & $4(8.7)$ & 0.509 \\
Mortality (n, \%) & $8(12.7)$ & $1(2.2)$ & 0.050 \\
MACCE events (n, \%) & & \\
Cardiac death & $3(4.8)$ & $1(2.2)$ & 0.478 \\
Myocardial infarction & $2(3.2)$ & $1(2.2)$ & 0.753 \\
Stroke & $2(3.2)$ & $1(2.2)$ & 0.753 \\
Heart failure & $3(4.8)$ & $0(0.0)$ & 0.133 \\
Stent thrombosis & $1(1.6)$ & $0(0.0)$ & 0.391 \\
Late catch-up phenomenon & $8(12.7)$ & $1(2.2)$ & 0.048 \\
\hline
\end{tabular}

MACCE, major cardiac and cerebrovascular events. Other abbreviations as in Table 1.

Computer package, version 5.0 (SAS Institute Inc, Cary, NC, USA). $\mathrm{P}<0.05$ was considered to indicate a statistically significant difference.

\section{Results}

Group P consisted of 63 patients, and Group $\mathrm{N}$ of 46 patients. The observation period was $7.43 \pm 1.62$ years.

\section{Clinical Characteristics of the Patient Population (Table 1)}

There were no differences between the groups in age, sex, body mass index, hypertension, DM, dyslipidemia, current smoking status, or family history. There were no differences between the groups in systolic blood pressure, diastolic blood pressure, hemoglobin A1c (HbA1c), low-density lipoproteincholesterol, high-density lipoprotein-cholesterol, or plasma triglycerides. There were also no differences between them in medications for hypertension, dyslipidemia, or DM (angiotensin-converting enzyme inhibitora, angiotensin-receptor blockers, calcium-channel blockers, sulfonylurea, alpha-glucosidase, and biguanide).

CAG Characteristics of the Patient Population (Table 2)

There were no differences between the 2 groups in lesion- related variables, number of diseased vessels, the ACC/AHA grading system, stent diameter, total stent length, or type of DES implanted (sirolimus-eluting stent and paclitaxel-eluting stent).

\section{Success Rate}

PCI was successful in all patients. There were no procedurerelated complications (acute stent thrombosis, stent fracture, stent deployment of failure, etc).

\section{Restenosis, Mortality and MACCE Rates (Table 3, Figure)}

Restenosis rate after 8 months was $12.7 \%$ in Group P, and $8.7 \%$ in Group N. This difference was not statistically significant. There were no differences between the groups in the occurrence of restenosis, death, cardiac death, myocardial infarction, stroke, heart failure, or stent thrombosis. However, the late catch-up phenomenon was significantly more common in Group P than in Group N (12.7\% vs. 2.2\%, P=0.048).

\section{Discussion}

We found no significant differences between the 2 study groups in the rates of death, cardiac death, myocardial infarction, stroke, heart failure, or stent thrombosis. However, the 
A: mortality

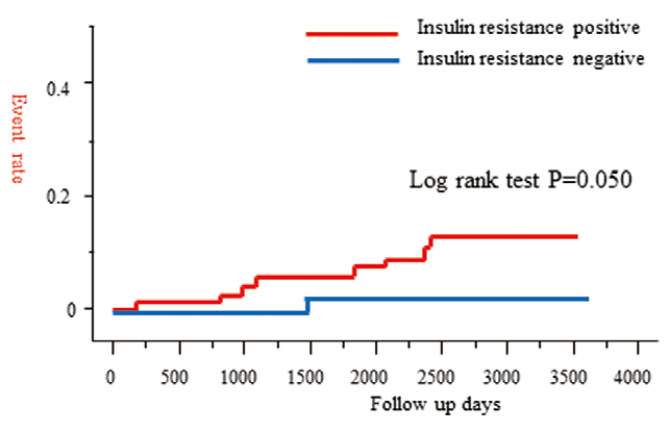

C: myocardial infarction

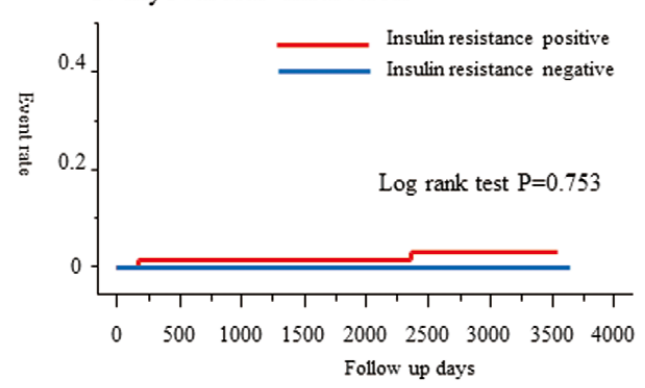

E: Heart failure

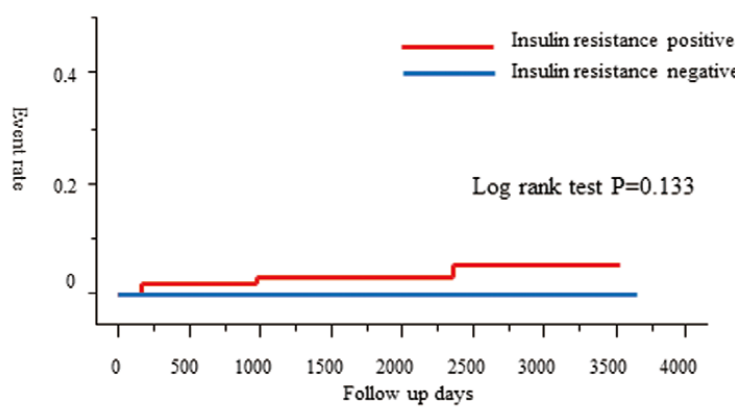

G: late catch up phenomenon

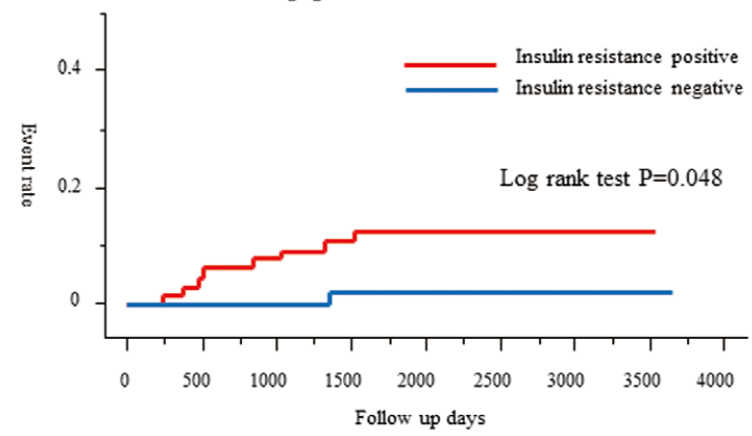

B: cardiac death
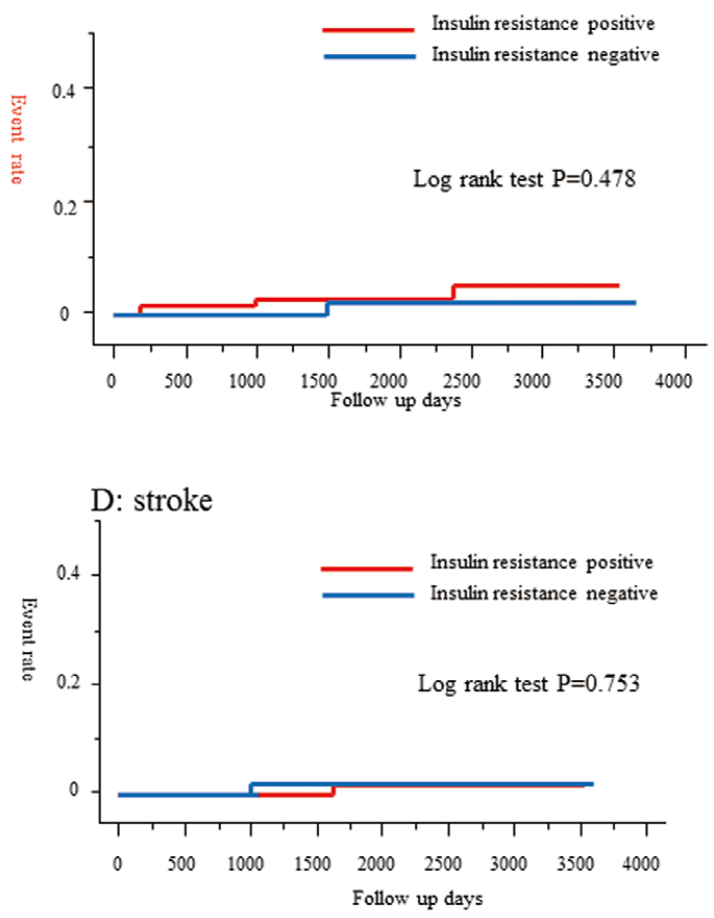

F: stent thrombosis

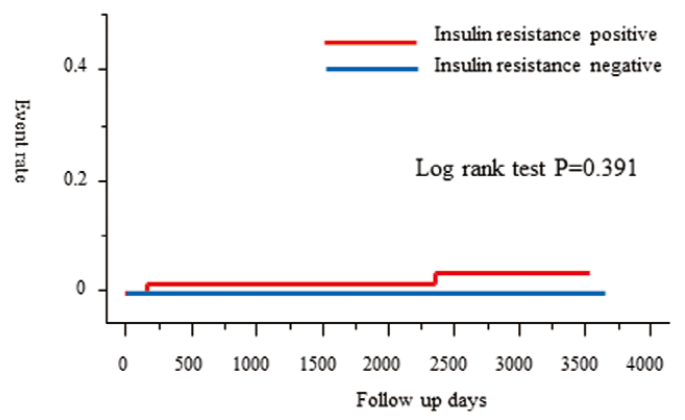

Figure. Kaplan-Meier curves based on insulin resistance of mortality and major adverse cardiac and cerebrovascular events (A: mortality, B: cardiac death, C: cardiac infarction, D: stroke, E: heart failure, F: stent thrombosis, G: late catch-up phenomenon). There were no differences between the groups in the occurrence of death, cardiac death, stroke, myocardial infarction, heart failure, or stent thrombosis. However, the late catch-up phenomenon was significantly more common in the positive group of insulin resistance than in the negative group $(\mathrm{P}=0.048)$. 
late catch-up phenomenon rate was significantly greater in Group P than in Group N. Stent implantation per se causes persistent inflammation of the tissues around the stent, because the stent is a foreign material and it continually stretches the vascular wall. ${ }^{13}$ The findings in this study suggested that neointimal tissue proliferation through inflammation might be promoted by IR even after DES implantation in the long-term.

\section{IR and MACCE}

IR is affected by several factors that are associated with ischemic heart disease. ${ }^{1,2}$ IR affects renin activity and causes hypertension, ${ }^{14}$ is associated with the abnormalities of lipoprotein metabolism found in hypertriglyceridemia, ${ }^{15}$ and is an independent risk factor for atherosclerosis. ${ }^{16}$ In this way, IR contributes to the initiation and progression of atherosclerosis, and is associated with increases in the rates of myocardial infarction and cardiac death.,17 However, the relationship between outcomes after DES implantation and IR is not clear. The present study found that IR was not associated with MACCE after DES implantation, possibly because patients with uncontrolled DM (fasting glucose $>200 \mathrm{mg} / \mathrm{dl}$ ) were excluded, as a consequence of which IR could not contribute to the clinical endpoints.

\section{IR and the Late Catch-up Phenomenon}

The rate of the late catch-up phenomenon in Group P was significantly greater than in Group N. The late catch-up phenomenon is a late restenosis occurring beyond 1 year. PCI causes laceration and dissection of the coronary vessel wall, which recovers by rebuilding neointimal tissue. Restenosis is caused by excessive proliferation of smooth muscle cells as neointimal tissue. ${ }^{18,19}$ This proliferative process of smooth muscle progresses excessively in patients with a high level of IR. Under such conditions, mitogen-activated protein kinase is activated, ${ }^{20}$ which in turn stimulates smooth muscle cell proliferation in the vessel wall. ${ }^{21}$ Inoue et al reported that high IR caused coronary artery endothelial cell dysfunction, ${ }^{22}$ which might also promote excessive smooth muscle cell proliferation in the vessel wall.

DES can reduce intimal hyperplasia in stented segments compared with bare-metal stents (BMS) ${ }^{23}$ However, the time course of restenosis for these 2 types of stent may be different. A serial angiographic study found that after BMS implantation, intimal hyperplasia peaked during the first 6 months, and lumen enlargement occurred from 6 months to 3 years after index stent implantation. ${ }^{24}$ In contrast, Byrne et al reported that ongoing late lumen loss beyond 8 months after the procedure was observed in angiographic data during 2 years of follow-up in 1,331 patients treated with DES. ${ }^{25}$ Nakagawa et al reported that in their 3-year follow-up data of the J-Cypher registry, the TLR rate after sirolimus-eluting stent implantation was $5.5 \%$ at 1 year, $8.1 \%$ at 2 years, and $10.0 \%$ at 3 years. ${ }^{26}$ Considering the results of our study, these TLR rates might increase in patients affected by IR. Others have reported that the late catch-up phenomenon might be associated with stent fracture and/or hemodialysis. ${ }^{27,28}$ However, the late catchup phenomenon in our study did not include any stent fracture and/or hemodialysis patients. IR in this study was associated with only the late catch-up phenomenon, not restenosis at 8 months after DES implantation. Although a DES can suppress acute phase inflammation strongly after stent implantation, it can also promote late-stage inflammation. ${ }^{29}$ Therefore, the small sample size and strong inflammatory suppression by the DES in the acute phase made the restenosis rate in Group P nearly equal to that in Group N, whereas the high rate of IR in Group
$\mathrm{P}$ promoted late-stage inflammation after DES implantation, which progressed to the late catch-up phenomenon. Therefore, it might be important to improve IR after DES implantation.

A recently developed new generation of DES has excellent outcomes compared with 1st-generation DES. ${ }^{30,31}$ However, there are many patients around the world in whom a 1st-generation DES was implanted and they are now living normal daily lives. Therefore, we need to treat patients with a 1stgeneration DES carefully for a long time, taking into consideration any change in IR.

\section{Future Strategy for Restenosis}

DES have been widely used in recent years. Although the restenosis rate after PCI has decreased, restenosis still occurs. The present study showed that IR may contribute to neointimal tissue proliferation after DES implantation. It is known that insulin has both growth-promoting and protective vascular effects in vivo. Breen et al showed that insulin increases neointimal growth after arterial injury. ${ }^{32}$ In clinical studies, Hoffmann et al showed no significant differences in the occurrence of major adverse cardiac events between BMS and DES in patients with metabolic syndrome. ${ }^{33}$ Metabolic syndrome is characterized by high IR, but Hoffmann et al did not evaluate IR. Our data show that the high IR group had a greater rate of the late catch-up phenomenon. Thus, an imbalance of insulin might promote endothelial dysfunction. In future, reducing IR may prevent the late catch-up phenomenon in patients who are given a DES.

Lately, pioglitazone hydrochloride has been used in diabetic patients and it was reported that the drug could improve IR and reduce the occurrence of cardiovascular events. ${ }^{34}$ However, IR is not limited to patients with DM. Therefore, we suggest that treatment of IR in the early phase in any patient may reduce the occurrence of the late catch-up phenomenon.

\section{Study Limitations}

There are 3 limitations in this study. First, this was a singlecenter non-randomized study. The relatively small number of patients limits the power of the study. Furthermore, the patients were evaluated only in the early postoperative period. Another study involving long-term follow-up of a larger number of patients is required to confirm our findings. Second, the HOMA-IR index cannot be calculated in patients using pioglitazone hydrochloride or insulin, and/or who have a fasting glucose $>200 \mathrm{mg} / \mathrm{dl}$. Therefore, another index of IR is necessary in such patients. Additionally, the evaluation of HOMAIR at 8-month follow-up and the degree of change in HOMA-IR between baseline and 8-month follow-up would be important in addition to the baseline level. We have also analyzed the data of HOMA-IR at 8-month follow-up, and found there was no significant difference from the HOMA-IR data at baseline. These findings suggest there is room for improvement in the treatment of IR. Third, 2nd-generation DES are replacing 1stgeneration DES worldwide, and patient outcomes have improved. However, even 2nd-generation DES DES provide non-uniform neointimal suppression in DM patients compared to non-DM patients. ${ }^{35}$ Therefore, further study of the late catch-up phenomenon after 2nd-generation DES implantation is also needed in patients with and without IR.

\section{Conclusions}

We suggest that IR promotes the late catch-up phenomenon after DES implantation. Accordingly, improvement of IR may help to prevent the phenomenon. 


\section{Conflict of Interest}

We have no conflicts of interest to declare in relation to this work.

\section{Acknowledgements}

None.

\section{References}

1. Reaven GM. Banting lecture 1988: Role of insulin resistance in human disease. Diabetes 1988; 37: 1595-1607.

2. DeFronzo RA, Ferrannini E. Insulin resistance: A multifaceted syndrome responsible for NIDDM, obesity, hypertension, dyslipidemia, and atherosclerotic cardiovascular disease. Diabetes Care 1991; 14: $173-194$

3. Wang H, Hu B, Lu W, Liu F, Feng B. Relationship of angiographically defined coronary artery disease with insulin sensitivity and secretion in subjects with different glucose tolerance. J Cardiol 2012; 60: $367-371$.

4. Hedblad B, Nilsson P, Engström G, Berglund G, Janzon L. Insulin resistance in non-diabetic subjects is associated with increased incidence of myocardial infarction and death. Diabet Med 2002; 19: $470-475$.

5. Ausk KJ, Boyko EJ, Ioannou GN. Insulin resistance predicts mortality in nondiabetic individuals in the U.S. Diabetes Care 2010; 33: $1179-1185$.

6. Komatsu T, Yaguchi I, Komatsu S, Nakahara S, Kobayashi S, Sakai $\mathrm{Y}$, et al. Impact of insulin resistance on neointimal tissue proliferation after 2 nd-generation drug-eluting stent implantation. Tex Heart Inst J 2015; 42: 327-332.

7. Buronova N, Kamishima K, Yamaguchi J, Jujo K, Watanabe E, Inagaki $\mathrm{Y}$, et al. Effect of hemodialysis on 7-year clinical outcomes after sirolimus-eluting stent implantation. Circ J 2015; 79: 21692176.

8. Sinha DP, Ahmed S, Baneerjee AK, Das M, Hassan H. Significance of an index of insulin resistance in non-diabetic patients with impaired fasting glucose with acute myocardial infarction and its correlation to short term outcome. Indian Heart J 2009; 61: 40-43.

9. Matthews DR, Hosker JP, Rudenski AS, Naylor BA, Treacher DF, Turner RC. Homeostasis model assessment: Insulin resistance and beta-cell function from fasting plasma glucose and insulin concentrations in man. Diabetologia 1985; 28: 412-419.

10. Kanauchi M. A new index of insulin sensitivity obtained from the oral glucose tolerance test applicable to advanced Type 2 diabetes. Diabetes Care 2002; 25: 1891-1892.

11. Gibbons RJ, Abrams J, Chatterjee K, Daley J, Deedwania PC, Douglas JS, et al. ACC/AHA 2002 guideline update for the management of patients with chronic stable angina--summary article: A report of the American College of Cardiology/American Heart Association Task Force on practice guidelines (Committee on the Management of Patients With Chronic Stable Angina). J Am Coll Cardiol 2003; 41: 159-168.

12. Smith SC Jr, Blair SN, Bonow RO, Brass LM, Cerqueira MD, Dracup K, et al. AHA/ACC guidelines for preventing heart attack and death in patients with atherosclerotic cardiovascular disease: 2001 update: A statement for healthcare professionals from the American Heart Association and the American College of Cardiology. J Am Coll Cardiol 2001; 38: 1581-1583.

13. Sato T, Takahashi M, Fujita D, Oba S, Nishimatsu H, Suzuki E, et al. Adipose-derived stem cells stimulate reendothelialization in stented rat abdominal aorta. Circ J 2014; 78: 1762-1769.

14. Iimura O, Shimamoto K, Masuda A, Higashiura K, Miyazaki Y, Hirata A, et al. Effects of a calcium channel blocker, manidipine, on insulin sensitivity in essential hypertensives. J Diabetes Complications 1995; 9: 215-219.

15. Abbott WG, Lillioja S, Young AA, Zawadzki JK, Yki-Järvinen H, Christin L, et al. Relationship between plasma lipoprotein concentrations and insulin action in an obese hyperinsulinemic population. Diabetes 1987; 36: 897-904.

16. Howard G, O'Leary DH, Zaccaro D, Haffner S, Rewers M, Hamman $\mathrm{R}$, et al. Insulin sensitivity and atherosclerosis. The Insulin Resistance Atherosclerosis Study (IRAS) investigators. Circulation 1996;
93: $1809-1817$.

17. Kuusisto J, Lempiäinen $P$, Mykkänen L, Laalso M. Insulin resistance syndrome predicts coronary heart disease events in elderly type 2 diabetic men. Diabetes Care 2001; 24: 1629-1633.

18. Ueda M, Becker AE, Tsukada T, Numano F, Fujimoto T. Fibrocellular tissue response after percutaneous transluminal coronary angioplasty: An immunocytochemical analysis of the cellular composition. Circulation 1991; 83: $1327-1332$.

19. Austin GE, Ratliff NB, Hollman J, Tabei S, Phillips DF. Intimal proliferation of smooth muscle cells as an explanation for recurrent coronary artery stenosis after percutaneous transluminal coronary angioplasty. J Am Coll Cardiol 1985; 6: 369-375.

20. Wang CC, Goalstone ML, Draznin B. Molecular mechanisms of insulin resistance that impact cardiovascular biology. Diabetes 2004; 53: $2735-2740$.

21. Bruemmer D. C-Peptide in insulin resistance and vascular complications: Teaching an old dog new tricks. Circ Res 2006; 99: 11491151.

22. Inoue T, Matsunaga R, Sakai Y, Yaguchi I, Takayanagi K, Morooka $\mathrm{S}$. Insulin resistance affects endothelium-dependent acetylcholineinduced coronary artery response. Eur Heart J 2000; 21: 895-900.

23. Kastrati A, Mehilli J, Pache J, Kaiser C, Valgimigli M, Kelbaek H, et al. Analysis of 14 trials comparing sirolimus-eluting stents with bare-metal stents. N Engl J Med 2007; 356: 1030-1039.

24. Kimura T, Yokoi H, Nakagawa Y, Tamura T, Kaburagi S, Sawada $\mathrm{Y}$, et al. Three-year follow-up after implantation of metallic coronary-artery stents. N Engl J Med 1996; 334: 561-566.

25. Byrne RA, Iijima R, Mehilli J, Pinieck S, Bruskina O, Schömig A, et al. Durability of antirestenotic efficacy in drug-eluting stents with and without permanent polymer. JACC Cardiovasc Interv 2009; 2: $291-299$.

26. Nakagawa Y, Kimura T, Morimoto T, Nomura M, Saku K, Haruta $\mathrm{S}$, et al. Incidence and risk factors of late target lesion revascularization after sirolimus-eluting stent implantation (3-year follow up of the Cypher Registry). Am J Cardiol 2010; 106: 329-336.

27. Serikawa T, Kawasaki T, Koga H, Orita Y, Ikeda S, Goto Y, et al. Late catch-up phenomenon associated with stent fracture after sirolimus-eluting stent implantation: Incidence and outcome. J Interv Cardiol 2011; 24: 165-171.

28. Iijima R, Araki T, Nagashima Y, Yamazaki K, Utsunomiya M, Hori $\mathrm{M}$, et al. Incidence and predictors of the late catch-up phenomenon after drug-eluting stent implantation. Int J Cardiol 2013; 168: $2588-2592$.

29. Taguchi I, Yoneda S, Abe S, Toyoda S, Nasuno T, Nishino S, et al. The late-phase inflammatory response after drug-eluting stent implantation. Heart Vessels 2014; 29: 213-219.

30. Grube E, Chevalier B, Smits P, Džavík V, Patel TM, Mullasari AS, et al. The SPIRIT V study: A clinical evaluation of the XIENCE V everolimus-eluting coronary stent system in the treatment of patients with de novo coronary artery lesions. JACC Cardiovasc Interv 2011; 4: $168-175$.

31. Kimura T, Morimoto T, Natsuaki M, Shiomi H, Igarashi K, Kadota $\mathrm{K}$, et al. Comparison of everolimus-eluting and sirolimus-eluting coronary stents: 1-year outcomes from the Randomized Evaluation of Sirolimus-eluting Versus Everolimus-eluting stent Trial (RESET). Circulation 2012; 126: 1225-1236.

32. Breen DM, Chan KK, Dhaliwall JK, Ward MR, Al Koudsi N, Lam $\mathrm{L}$, et al. Insulin increases reendothelialization and inhibits cell migration and neointimal growth after arterial injury. Arterioscler Thromb Vasc Biol 2009; 29: 1060-1066.

33. Hoffmann R, Stellbrink E, Schroder J, Grawe A, Vogel G, Blindt R, et al. Impact of the metabolic syndrome on angiographic and clinical events after coronary intervention using bare-metal or sirolimuseluting stents. Am J Cardiol 2007; 100: 1347-1352.

34. Lincoff AM, Wolski K, Nicholls SJ, Nissen SE. Pioglitazone and risk of cardiovascular events in patients with type 2 diabetes mellitus: A meta-analysis of randomized trials. JAMA 2007; 298: 1180 1188.

35. Iwasaki M, Otake H, Shinke T, Nakagawa M, Hariki H, Hirata K, et al. Vascular responses in patients with and without diabetes mellitus after everolimus-eluting stent implantation: Optical Coherence Tomography Study. Circ J 2014; 78: 2188-2196. 